\title{
Digestibilidade do cálcio de ingredientes para suínos, avaliada por meio de dois métodos
}

[Calcium digestibility from feedstuffs for pigs evaluated using two methods]

\author{
S.C. Salguero ${ }^{1}$, H.S. Rostagno ${ }^{2}$, M.I. Hannas $^{2}$, T.A. Carvalho ${ }^{1}$, R.C. Maia ${ }^{1}$, G.B.S. Pessoa ${ }^{1}$ \\ ${ }^{1}$ Aluno de pós-graduação - Universidade Federal de Viçosa - Viçosa, MG \\ ${ }^{2}$ Universidade Federal de Viçosa - Viçosa, MG
}

\begin{abstract}
RESUMO
Determinaram-se os coeficientes de digestibilidade aparente e verdadeira do cálcio $(\mathrm{Ca})$ de ingredientes para suínos por meio de dois métodos. Foram utilizados 60 suínos machos castrados, alojados em gaiolas de metabolismo e distribuídos em delineamento experimental inteiramente ao acaso, em arranjo fatorial 2 x 10 (métodos x tratamentos) e seis repetições por tratamento. Os tratamentos consistiram em oito alimentos, uma ração basal $(0,072 \%$ de Ca total) e uma ração com baixo teor de $\mathrm{Ca}(0,018 \%)$. Os coeficientes de digestibilidade aparente e verdadeira do $\mathrm{Ca}$ foram avaliados utilizando-se simultaneamente dois métodos: coleta total de fezes e coleta de fezes com indicador fecal (cinza ácida insolúvel - CAI). Os coeficientes de digestibilidade verdadeira do $\mathrm{Ca}$, obtidos pelo método de coleta total e pelo método de indicador fecal, foram, respectivamente: calcário calcítico 1, 84,80 e 87,33\%; calcário calcítico 2, 84,19 e 86,32\%; fosfato bicálcico, 79,36 e 84,55\%; fosfato monobicálcico, 83,83 e 85,81\%; calcário dolomítico, 85,65 e 87,39\%; farinha de carne e ossos (40\% PB), 70,00 e 68,64\%; farinha de carne e ossos (50\% PB), 66,92 e 68,03\%; farinha de vísceras, 73,40 e 73,95\%, lactato de Ca, 95,10 e $97,33 \%$. Não houve diferença significativa $(P>0,05)$ entre os métodos avaliados coleta total $(80,14 \%)$ e indicador fecal $(82,15 \%)$.
\end{abstract}

Palavras-chave: suíno, cálcio, cinza ácida insolúvel, digestibilidade, indicador fecal

\begin{abstract}
The coefficients of apparent and true digestibility of calcium (Ca) of eight feedstuffs for pigs were determined. A total of 60 barrows were housed in metabolism cages and distributed in a completely randomized design in a factorial $2 \times 10$ (treatments $X$ methods) and 6 replicates per treatment. Treatments consisted of eight feedstuffs, a basal diet $(0.072 \% \mathrm{Ca})$ and a diet with low Ca content $(0.018 \%)$. The coefficients of apparent and true digestibility of Ca were determined using two methods simultaneously: total fecal collection and fecal marker (Acid Insoluble Ash-AIA). The true digestibility coefficients of $\mathrm{Ca}$, obtained by the total fecal collection and the fecal marker methods were respectively: Limestone 1, 84.80 and 87.33\%; Limestone 2, 84.19\% and 86.32; Dicalcium Phosphate, 79.36 and 84.55\%; Monodicalcium Phosphate, 83.83 and 85.81\%, Dolomitic Limestone, 87.39\% and 85.65; Meat and Bone Meal (40\% CP), 70.00 and 68,64\%; Meat and Bone Meal (50\% CP), 66.92\% and 68.03; Poultry by Product Meal, 73.40 and 73.95\%, Calcium Lactate, 95.10 and 97.33\%. There was no significant difference $(P>0.05)$ between the total fecal collection $(80.14 \%)$ and fecal marker $(82.15 \%)$ with the methods evaluated.
\end{abstract}

Keywords: suine, acid insoluble ash calcium, digestibility, fecal marker

Recebido em 16 de junho de 2013

Aceito em 19 de fevereiro de 2014

E-mail: sankarolina@yahoo.es 


\section{INTRODUÇÃO}

Os minerais possuem papel importante na nutrição dos suínos, pois a deficiência ou o excesso dietético impossibilita a expressão do máximo desempenho na fase de crescimento. Segundo Fawcett e Webster (1999), as variações nos valores nutritivos das raçoes, principalmente os níveis dos nutrientes nos ingredientes, são a principal causa dos desvios entre o desempenho esperado e o observado nos animais. Por isso se faz necessário aprimoramento do conhecimento da composição química das matérias-primas, comumente utilizadas na alimentação animal, sendo indispensável a revisão constante dos valores de disponibilidade ou da digestibilidade.

Muitas vezes, os termos digestibilidade e disponibilidade são utilizados como sinônimos. No entanto, essa denominação varia conforme o local do animal onde o nutriente é avaliado. Segundo Sakomura e Rostagno (2007), a digestibilidade é determinada pela diferença entre a quantidade de nutriente consumido e a excretada nas fezes; já a disponibilidade inclui os processos de digestão, absorção e metabolismo ou a utilização deles, sendo definida como a quantidade de nutriente absorvido e utilizado pelo animal. A disponibilidade dos minerais é determinada em ensaios de crescimento, nos quais a utilização destes é avaliada por meio de parâmetros de desempenho e/ou deposição nos ossos pelos animais.

Vários trabalhos de pesquisas têm sido desenvolvidos com o objetivo de atualizar os valores nutricionais dos alimentos tradicionalmente utilizados na formulação de dietas para suínos, além de buscar conhecer o valor nutritivo de novos alimentos e subprodutos, o que torna as tabelas de composição mais completas e com valores mais precisos (Lelis et al., 2009). No entanto, não existem na literatura valores de cálcio $(\mathrm{Ca})$ digestível dos alimentos para suínos, o que pode ser explicado pelo baixo custo das fontes de $\mathrm{Ca}$ nas rações. As exigências são expressas na forma de cálcio total, o que pode resultar em excesso e, como consequência, gerar o antagonismo com outros minerais, dificultando, assim, sua digestibilidade (Fernandez, 1995).

O cálcio está intimamente ligado ao fósforo, e uma deficiência ou excesso de um deles pode diminuir a disponibilidade e a digestibilidade do outro, o que provoca, consequentemente, sua excreção ao meio ambiente (Selle et al., 2008).

Desta forma, o presente trabalho foi realizado com o objetivo de determinar os valores dos coeficientes de digestibilidade aparente e verdadeira do cálcio de alguns ingredientes comumente utilizados nas formulações de rações para suínos em crescimento, por meio de dois métodos.

\section{MATERIAL E MÉTODOS}

O experimento foi conduzido no Setor de Suinocultura do Departamento de Zootecnia da Universidade Federal de Viçosa, de acordo com as recomendações do comitê de ética do Departamento de Zootecnia, processo no. 20/2013.

Foram utilizados 60 suínos, machos castrados e híbridos comerciais, com peso médio inicial e final de $22,0 \pm 2,0 \mathrm{~kg}$ e $43,8 \pm 2,3 \mathrm{~kg}$ respectivamente, distribuídos em um delineamento experimental inteiramente ao acaso, em arranjo fatorial 2 x 10 (dois métodos $\mathrm{x}$ 10 tratamentos) com seis repetições. Foram avaliados simultaneamente dois métodos: coleta total de fezes com e sem indicador fecal.

Os tratamentos consistiram em oito alimentos, uma ração basal à base de milho e farelo de soja contendo $0,072 \%$ do Ca total, de modo a atender as exigências dos animais segundo Rostagno et al. (2011), exceto para cálcio e fósforo, e uma dieta de baixo cálcio contendo $0,018 \%$ de $\mathrm{Ca}$ total utilizada para determinar as perdas endógenas dos animais (Tab. 1). Os alimentos avaliados substituíram a ração basal, em quantidades variadas, de modo a fornecer $0,30 \%$ de Ca total.

A porcentagem de substituição da ração basal pelos alimentos foi: calcário calcítico 1 $(0,781 \%)$, calcário calcítico $2(0,781 \%)$, fosfato bicálcico $(1,225 \%)$, fosfato monobicálcico (1,5\%), calcário dolomítico $(1,613 \%)$, farinha carne e ossos $(40 \%$ proteína bruta - PB) $(2,976 \%)$, farinha carne e ossos $(50 \%$ proteína bruta - PB) $(3,29 \%)$, farinha de vísceras $(7,5 \%)$, lactato de cálcio $(0,781 \%)$. 
Tabela 1. Composição centesimal da ração basal e a de baixo cálcio

\begin{tabular}{|c|c|c|}
\hline Ingredientes & $\begin{array}{c}\text { Ração } \\
\text { basal }(\%)\end{array}$ & $\begin{array}{c}\text { Ração } \\
\text { baixo Ca } \\
(\%)\end{array}$ \\
\hline Milho moído & 71,83 & - \\
\hline Milho pré-cozido & - & 90,00 \\
\hline Sabugo de milho & 0,50 & 3,70 \\
\hline Farelo de soja & 19,05 & - \\
\hline Óleo de Soja & 1,50 & 2,00 \\
\hline Açúcar & 3,00 & - \\
\hline Amido & - & 1,00 \\
\hline Carbonato de potássio & - & 0,65 \\
\hline Plasma sanguíneo & 2,50 & - \\
\hline Sal comum & 0,21 & 0,47 \\
\hline Suplemento vitamínico ${ }^{2}$ & 0,06 & 0,10 \\
\hline Suplemento mineral $^{1}$ & 0,10 & 0,05 \\
\hline DL-Metionina (99\%) & 0,03 & 0,05 \\
\hline L-Lisina $\mathrm{HCl}(99 \%)$ & 0,15 & 0,32 \\
\hline L-Treonina $(98 \%)$ & - & 0,07 \\
\hline L-Valina (99\%) & - & 0,04 \\
\hline L-Arginina (99\%) & - & 0,22 \\
\hline Glicina & - & 0,15 \\
\hline L-Triptofano (99\%) & - & 0,04 \\
\hline L-Isoleucina (99\%) & - & 0,03 \\
\hline Cloreto de colina $(60 \%)$ & 0,06 & 0,10 \\
\hline Antioxidante & 0,01 & 0,01 \\
\hline Indicador fecal (CAI) & 1,00 & 1,00 \\
\hline \multicolumn{3}{|l|}{ Composição calculada } \\
\hline Cálcio (\%) & 0,072 & 0,018 \\
\hline Fósforo disponível (\%) & 0,103 & 0,054 \\
\hline Fósforo total (\%) & 0,284 & 0,162 \\
\hline \multicolumn{3}{|l|}{ Composição analisada } \\
\hline Cálcio (\%) & 0,071 & 0,017 \\
\hline Fósforo total (\%) & 0,281 & 0,160 \\
\hline
\end{tabular}

${ }^{1} 1 \mathrm{~g} / \mathrm{kg}$ de ração de suplemento mineral contendo, por $\mathrm{kg}$ de ração: ferro - 55,0mg; cobre - 11,0mg; manganês - 77,0mg; zinco - 71,5mg; iodo - 1,10mg; $1,6 \mathrm{~g} / \mathrm{kg}$ de ração de suplemento vitamínico contendo, por kg de ração: vit. A - 8250UI; vit. D3 - 2090UI; vit. $\mathrm{E}-31.0 \mathrm{UI}$; vit. B1 - 2,20mg; vit. B2 - 5,50mg; vit. B6 - 3,08mg; vit. B12 - 0,013mg; ácido pantotênico - $11,0 \mathrm{~g}$; biotina $-0,077 \mathrm{mg}$; vit. K3 $1,65 \mathrm{mg}$; ácido fólico - 0,77mg; ácido nicotínico $33,0 \mathrm{mg}$; selênio $-0,330 \mathrm{mg}$.

A cada ração experimental foi adicionado $1 \%$ de cinza ácida insolúvel - Celite (CAI), usada como indicador fecal. A quantidade de ração a ser fornecida a cada animal foi determinada $\underset{0,75}{\mathrm{em}}$ função do peso metabólico dos animais (peso ${ }^{0,75}$ ) em duas refeições diárias, às oito e às 17:00 horas, e a água foi fornecida à vontade.

O período experimental foi de 10 dias, sendo cinco dias de adaptação ás rações experimentais e ás gaiolas e cinco dias de coleta total de fezes e urina.

As fezes excretadas no período de 24 horas foram coletadas em sacos plásticos e armazenadas em freezer $\left(-18^{\circ} \mathrm{C}\right)$ até o final do período de coleta (cinco dias). Depois deste período, as fezes foram descongeladas, homogeneizadas e secas em estufa ventilada a $55^{\circ} \mathrm{C}$, por um período de 72 horas. Posteriormente, as amostras foram moídas e armazenadas em potes plásticos para sua análise.

A urina excretada pelos animais foi filtrada e recolhida em baldes plásticos contendo $\mathrm{HCl}$, para, assim, evitar a proliferação bacteriana, e foi armazenada em geladeira $\left(3^{\circ} \mathrm{C}\right)$ até o final do período de coleta (cinco dias). Depois deste período, a urina foi homogeneizada, e retirou-se uma alíquota de $10 \mathrm{~mL}$ que foi mantida sob refrigeração para posterior análise.

As análises dos teores de matéria seca e cálcio foram realizadas de acordo com as metodologias descritas por Silva e Queiroz (2002), e as análises do indicador fecal (CAI) foram realizadas segundo a metodologia descrita por Joselyn (1970). Foi determinado o diâmetro geométrico médio e o desvio-padrão médio dos ingredientes testados conforme a metodologia descrita no AOAC (1990).

Foram determinados o consumo de matéria seca (g/dia), o consumo de cálcio total, o consumo de cálcio da ração basal e dos alimentos (g/dia), o cálcio na ração, nas fezes e na urina (\%), a excreção de cálcio (g/dia), o fator de indigestibilidade, $\mathrm{o}$ fator de indigestibilidade endógena e o cálcio excretado pelos animais que receberam a dieta com baixo teor de cálcio (cálcio endógeno, g/dia). Os dados obtidos foram usados nas fórmulas descritas por Jongbloed e Kemme (1990) e Rostagno e Featherston (1977) para a obtenção dos coeficientes de digestibilidade aparente (CDACa) e verdadeira (CDVCa) do cálcio. 
1. Método coleta total de fezes

coeficiente do cálcio digestível aparente (CRACa)

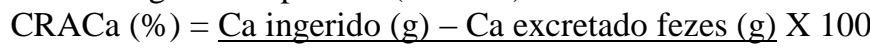

$\mathrm{Ca}$ ingerido $(\mathrm{g})$

coeficiente do cálcio digestível verdadeiro (CRVCa)

CRVCa $(\%)=[$ Ca ingerido $(\mathrm{g})-($ Ca excretado fezes $(\mathrm{g})-\mathrm{Ca}$ endógeno $(\mathrm{g}))]$ X 100

Ca ingerido $(\mathrm{g})$

2. Método do indicador fecal (CAI)

fator de indigestibilidade (FI)

$\mathrm{FI}=\underline{\% \mathrm{CAI} \text { dieta }}$

$\%$ CAI fezes

coeficiente de digestibilidade aparente do cálcio (CDACa)

$\mathrm{CDACa}(\%)=\underline{\% \text { Ca dieta }-(\% \text { Ca fezes X FI })} \times 100$

$\%$ Ca dieta

coeficiente de digestibilidade verdadeira do $\mathrm{Ca}(\mathrm{CDVCa})$

$$
\mathrm{CDVCa}(\%)=\frac{\% \mathrm{Ca} \text { dieta }-(\% \mathrm{Ca} \text { fezes } \times \mathrm{FI}-\% \mathrm{Cae} \times \mathrm{FIe})}{\% \mathrm{Ca} \text { dieta }} 100
$$

em que:

FIe = fator de indigestibilidade da dieta baixo cálcio;

$\mathrm{Cae}=$ cálcio endógeno excretado.

Os dados obtidos foram submetidos à análise de variância, seguidos do teste de Dunnett, para comparar os alimentos usando o calcário calcítico 1 como contraste. Foi utilizado o pacote estatístico SAEG (Sistema..., 2001), desenvolvido na Universidade Federal de Viçosa.

\section{RESULTADOS E DISCUSSÃO}

A média das temperaturas máxima e mínima, no período experimental, foi de 16 e $22^{\circ} \mathrm{C}$, respectivamente. A excreção endógena obtida para suínos foi de 0,299g/animal/dia (0,541g/animal/kg MS consumida), estimada

para animais com peso médio de $22 \mathrm{~kg}$ em $0,029 \mathrm{~g}$ $\mathrm{Ca} /$ peso $^{0,75}$. Fernandez (1995), ao medir a digestibilidade do cálcio radioativo em suínos em crescimento, estimou as perdas endógenas em 0,546g Ca/animal/dia $(0,988 \mathrm{~g} \mathrm{Ca} /$ animal/kg MS consumida) e citou excreção de $0,038 \mathrm{~g}$ $\mathrm{Ca} /$ peso $^{0,75}$ para animais com peso médio de $35 \mathrm{~kg}$, valores estes superiores aos encontrados neste trabalho.

$\mathrm{Na}$ Tab. 2, são apresentados os conteúdos de cálcio total e os valores do diâmetro geométrico médio (DGM) e do desvio-padrão geométrico (DPG) dos ingredientes avaliados em suínos.

Tabela 2. Conteúdo de cálcio total (Ca total) e valores do diâmetro geométrico médio (DGM) e do desvio-padrão geométrico (DPG) dos ingredientes avaliados em suínos (na MN)

\begin{tabular}{lccc}
\multicolumn{1}{c}{ Alimentos } & Ca total $(\%)^{1}$ & DGM $^{1}$ & DPG $^{1}$ \\
\hline Calcário calcítico 1 & 36,69 & $607 \mu \mathrm{m}$ & 2,76 \\
Calcário calcítico 2 & 36,05 & $630 \mu \mathrm{m}$ & 2,78 \\
Fosfato bicálcico & 20,58 & $660 \mu \mathrm{m}$ & 2,30 \\
Fosfato monobicálcico & 18,32 & $593 \mu \mathrm{m}$ & 2,62 \\
Calcário dolomítico & 25,04 & $432 \mu \mathrm{m}$ & 1,85 \\
Farinha carne e ossos 40\% PB & 15,10 & $584 \mu \mathrm{m}$ & 1,47 \\
Farinha carne e ossos 50\% PB & 9,51 & $630 \mu \mathrm{m}$ & 2,31 \\
Farinha de vísceras & 5,40 & $644 \mu \mathrm{m}$ & 1,45 \\
Lactato de cálcio & 19,35 & $384 \mu \mathrm{m}$ & 2,15 \\
\hline
\end{tabular}

${ }^{\mathrm{I}}$ Valores determinados. 
Os ingredientes que apresentaram um DGM maior foram o fosfato bicálcico $(660 \mu \mathrm{m})$, a farinha de vísceras $(644 \mu \mathrm{m})$ e a farinha de carne e ossos de $50 \%$ PB $(630 \mu \mathrm{m})$, e os que apresentarem um menor DGM foram o lactato de cálcio $(384 \mu \mathrm{m})$ e o calcário dolomítico $(432 \mu \mathrm{m})$.

Trabalhos têm mostrado que o tamanho de partícula é o fator mais determinante na disponibilidade do cálcio e do fósforo nos fosfatos desfluorizados (Ammerman et al., 1995). No entanto, Ross et al. (1984), ao avaliarem a disponibilidade do calcário calcítico com DGM entre 0,11 e $0,40 \mathrm{~mm}$ e do calcário dolomítico com DGM entre 0,06 e $0,24 \mathrm{~mm}$ para suínos em crescimento, verificaram que o tamanho de partícula não influenciou a disponibilidade do cálcio das fontes testadas no parâmetro ósseo avaliado e estimaram disponibilidade de $99 \%$ para o calcário calcítico e de $78 \%$ para o calcário dolomítico.

A urina dos animais experimentais foi analisada por meio do espectrofotômetro de absorção atômica segundo a metodologia de Silva e Queiroz (2002). Não foram encontrados valores de cálcio nas amostras analisadas. Bindels (1993) cita que aproximadamente $98 \%$ do cálcio filtrado é reabsorvido ao longo de todo o néfron nos mamíferos. Esse processo é regulado hormonalmente, sobretudo pelo PTH e pela vitamina $\mathrm{D}$, os quais respondem ao consumo de cálcio. Igualmente, Benson et al. (1964) informaram que os animais respondem a um mecanismo adaptativo de acordo com a ingestão de cálcio dietético; assim, quando o consumo é baixo, o animal tem a capacidade de aumentar a retenção deste, de modo a ativar os sistemas de absorção transcelular no intestino e a reabsorção nos rins por meio do estímulo do PTH. Esse fato, somado ao baixo nível de cálcio e fósforo dietético nas rações dos animais experimentais, pode explicar a não detecção de valores de cálcio na urina dos animais.

Os valores médios dos coeficientes de digestibilidade aparente (CDA) e verdadeira (CDV) do cálcio dos ingredientes avaliados, para suínos em crescimento, encontram-se na Tab. 3.

Não houve diferença significativa entre os métodos de coleta total e do indicador fecal
$(\mathrm{P}>0,05)$ sobre os coeficientes de digestibilidade aparente $(80,36$ e $81,96 \%$, respectivamente) e verdadeira do cálcio $(80,14$ e $82,15 \%$, respectivamente). O método de coleta total foi o que proporcionou menor valor numérico, tanto nos coeficientes de digestibilidade aparente quanto nos coeficientes de digestibilidade verdadeira, em comparação ao método do indicador. Cheng e Coon (1990) relatam que a CAI pode aumentar a digestibilidade dos nutrientes devido à alta ingestão de sílica. Níveis superiores a $2 \%$ na dieta podem reduzir a passagem da digesta no intestino e, assim, melhorar a digestibilidade dos nutrientes, entretanto valores obtidos nas rações experimentais $(1,082 \pm 0,078 \%$ de CAI) foram menores a esse valor, o que possivelmente não teve efeito sobre a digestibilidade do $\mathrm{Ca}$.

Os resultados obtidos estão de acordo com Ly et al. (2001), que compararam o método de coleta total de fezes com o método do indicador fecal utilizando CAI, em suínos. Não encontraram diferenças significativas $(\mathrm{P}>0,05)$ entre os dois métodos, nos coeficientes de digestibilidade da matéria seca $(80,0$ e $81,0 \%)$, fibra em detergente neutro (80,2 e 79,9\%) e nitrogênio $(84,6$ e $84,1 \%$ ), respectivamente. Os resultados também são semelhantes aos relatados por Grageola et al. (2011), que, ao compararem dois genótipos e os métodos de coleta total e do indicador fecal usando a CAI em suínos em crescimento, não encontraram diferenças significativas $(\mathrm{P}>0,05)$ nos coeficientes de digestibilidade da matéria seca $(86,9$ e $85,2 \%)$, do nitrogênio $(83,1$ e $84,4 \%)$ e da energia $(84,9$ e $84,3 \%)$, respectivamente.

Sales e Janssens (2003) compararam estudos de digestibilidade com o método de coleta total e do indicador fecal usando a CAI em diferentes alimentos e espécies. Dos 45 trabalhos analisados, 26 apresentaram resultados similares entre os dois métodos em estudo, nove subestimaram os valores de digestibilidade com o uso de CAI e 10 os superestimaram. Desta forma, a CAI é considerada um indicador confiável com diversas vantagens que podem ser usadas com sucesso para determinar a digestibilidade fecal em diferentes espécies. 
Tabela 3. Coeficientes de digestibilidade aparente (CDA) e verdadeira (CDV) de Ca dos diferentes ingredientes para suínos, por meio de dois métodos

\begin{tabular}{|c|c|c|c|c|c|c|}
\hline \multirow[b]{2}{*}{ Alimentos } & \multicolumn{2}{|c|}{$\mathrm{CDA}^{1}$} & \multirow[b]{2}{*}{$\begin{array}{c}\text { Média } \\
(\%)\end{array}$} & \multicolumn{2}{|c|}{$\mathrm{CDV}^{2}$} & \multirow[b]{2}{*}{$\begin{array}{l}\text { Média } \\
(\%)\end{array}$} \\
\hline & $\begin{array}{c}\text { Coleta total } \\
(\%)\end{array}$ & $\begin{array}{c}\text { Indicador fecal } \\
(\%)\end{array}$ & & $\begin{array}{c}\text { Coleta total } \\
(\%)\end{array}$ & $\begin{array}{l}\text { Indicador } \\
\text { fecal }(\%)\end{array}$ & \\
\hline $\begin{array}{l}\text { Calcário } \\
\text { calcítico } 1\end{array}$ & 84,79 & 87,02 & $85,91 \pm 0,91$ & 84,80 & 87,33 & $86,06 \pm 1,03$ \\
\hline $\begin{array}{l}\text { Calcário } \\
\text { calcítico } 2\end{array}$ & 84,19 & 86,21 & $85,20 \pm 0,83$ & 84,19 & 86,32 & $85,26 \pm 0,87$ \\
\hline Fosfato bicálcico & 79,35 & 84,54 & $81,95 \pm 2,12$ & 79,36 & 84,55 & $81,95 \pm 2,12$ \\
\hline $\begin{array}{l}\text { Fosfato } \\
\text { monobicálcico }\end{array}$ & 83,83 & 86,13 & $84,48 \pm 0,53$ & 83,83 & 85,81 & $84,82 \pm 0,81$ \\
\hline $\begin{array}{l}\text { Calcário } \\
\text { dolomítico }\end{array}$ & 85,64 & 87,19 & $86,41 \pm 0,63$ & 85,65 & 87,39 & $86,52 \pm 0,71$ \\
\hline $\begin{array}{l}\text { Farinha carne e } \\
\text { ossos } 40 \% \text { PB }\end{array}$ & 70,02 & 68,80 & $69,41 \pm 0,50^{*}$ & 68,00 & 68,64 & $68,32 \pm 0,56^{*}$ \\
\hline $\begin{array}{l}\text { Farinha carne e } \\
\text { ossos } 50 \% \text { PB }\end{array}$ & 66,91 & 67,81 & $67,36 \pm 0,30 *$ & 66,92 & 68,03 & $67,48 \pm 0,39 *$ \\
\hline $\begin{array}{l}\text { Farinha de } \\
\text { vísceras }\end{array}$ & 73,39 & 73,80 & $73,59 \pm 0,17 *$ & 73,40 & 73,95 & $73,68 \pm 0,22 *$ \\
\hline Lactato de cálcio & 95,10 & 97,11 & $96,11 \pm 0,82 *$ & 95,10 & 97,33 & $96,21 \pm 0,91 *$ \\
\hline Média $^{3}$ & $80,36 \pm 2,96 \mathrm{a}$ & $81,96 \pm 2,72 \mathrm{a}$ & & $80,14 \pm 2,96 a$ & $82,15 \pm 2,76 a$ & \\
\hline \multicolumn{7}{|c|}{$\begin{array}{l}{ }^{1} \text { Coeficiente de variação }=6,18 \% \text {. } \\
{ }^{2} \text { Coeficiente de variação }=6,15 \% \text {. } \\
{ }^{3} \text { Média do método } \pm \text { erro-padrão da }\end{array}$} \\
\hline
\end{tabular}

Em comparação ao calcário calcítico 1, o alimento que apresentou a melhor digestibilidade foi o lactato de $\mathrm{Ca}$, tanto nos coeficientes de digestibilidade aparente como nos coeficientes de digestibilidade verdadeira $(96,10$ e $96,21 \%$, respectivamente). Isso pode ser explicado pelo fato de que o $\mathrm{Ca}$, na presença de lactose, forma um complexo que auxilia na redução do $\mathrm{pH}$ devido à formação de ácidos produzidos por fermentação bacteriana e inibição do metabolismo celular aeróbico, o que aumenta a digestibilidade do Ca (Lindsay et al., 1982). Igualmente, Greger et al. (1987) determinaram a absorção aparente de $\mathrm{Ca}$ do lactato de $\mathrm{Ca}$ em ratos desmamados e verificaram a alta digestibilidade dessa fonte de $\mathrm{Ca}(104 \%)$.

O valor médio do coeficiente de digestibilidade aparente obtido para o calcário calcítico 1 $(85,91 \%)$ foi superior ao apresentado por Fernandez (1995), o qual, com o uso de isótopos radioativos, avaliou a digestibilidade do $\mathrm{Ca}$ e encontrou valores de $65,0 \%$ para a digestibilidade aparente do carbonato de $\mathrm{Ca}$.

Os ingredientes que apresentaram menores coeficientes de digestibilidade aparente e verdadeira foram: farinha de carne e ossos $40 \%$
PB (CDA 69,32\% e CDV 69,41\%), farinha de carne e ossos $50 \%$ PB (CDA 67,36\% e CDV $67,48 \%$ ) e farinha de vísceras (CDA 73,67\% e CDV 73,59\%). Lindsay et al. (1982) relataram que o consumo elevado de proteínas está relacionado com a diminuição na absorção de $\mathrm{Ca}$ e o aumento de excreção renal, o que pode explicar os baixos coeficientes de digestibilidade tanto aparente quanto verdadeira encontrados nesses ingredientes.

Segundo Loghman-Adham (1993), o cálcio e o fósforo estão intimamente ligados e o excesso ou a deficiência de um deles provoca desequilíbrio na sua relação exata, o que afeta negativamente a eficiência da absorção; esta resposta adaptativa depende do aporte dietético da fonte desses minerais. As farinhas de carne e ossos (40 e 50\% PB) e a farinha de vísceras possuem uma alta quantidade de cálcio e fósforo (13,07 e 6,53\%, 10,56 e $5,28 \% ; 4,34$ e $4,68 \%$, respectivamente, segundo Rostagno et al., 2011), o que pode afetar seu balanço exato no intestino e, como consequência, provocar a diminuição da sua digestibilidade. É possível que os alimentos de origem animal, devido ao seu alto conteúdo e desequilíbrio de $\mathrm{Ca}$ e $\mathrm{P}$, 
influenciem negativamente a digestibilidade desses nutrientes.

Os ingredientes de origem inorgânica apresentaram as maiores médias dos coeficientes de digestibilidade verdadeira de $\mathrm{Ca}$ : calcário calcítico $1(86,06 \%)$, calcário calcítico 2 $(85,26 \%)$, fosfato bicálcico $(81,95 \%)$, fosfato monobicálcico $(84,82 \%)$, calcário dolomítico $(87,39 \%)$ e lactato de cálcio $(96,21 \%)$. Ammerman et al. (1995) apresentam valores de disponibilidade do cálcio para suínos, obtidos por diferentes autores, sendo $80 \%$ para o carbonato de cálcio PA, 99\% para o calcário calcítico e $78 \%$ para o calcário dolomítico, em experimentos em que o parâmetro avaliado foi a força de quebra do osso.

Os teores de $\mathrm{Ca}$ total e de $\mathrm{Ca}$ digestível verdadeiro dos ingredientes, obtidos utilizandose os valores médios dos coeficientes de digestibilidade verdadeira para suínos encontram-se na Tab. 4.

Tabela 4. Conteúdo de cálcio total (Ca total) e de cálcio digestível verdadeiro ( $\mathrm{Ca}$ dig) dos ingredientes para suínos em crescimento

\begin{tabular}{lcc}
\hline Alimentos & $\begin{array}{c}\text { Ca total } \\
(\%)\end{array}$ & $\begin{array}{c}\text { Ca dig } \\
(\%)\end{array}$ \\
\hline Calcário calcítico 1 & 36,69 & 31,58 \\
Calcário calcítico 2 & 36,05 & 30,74 \\
Fosfato bicálcico & 20,58 & 16,87 \\
Fosfato monobicálcico & 18,32 & 15,54 \\
Calcário dolomítico & 25,04 & 21,66 \\
Farinha carne e ossos & 15,10 & 10,32 \\
40\% PB & & \\
Farinha carne e ossos & 9,51 & 6,42 \\
50\% PB & 5,40 & 3,98 \\
Farinha de vísceras & 19,35 & 18,62 \\
\hline Lactato de cálcio & &
\end{tabular}

\section{CONCLUSÕES}

Os métodos de coleta total de fezes e do indicador fecal usando a CAI para a determinação da digestibilidade do cálcio podem ser utilizados para a determinação da digestibilidade do cálcio em ingredientes para suínos. Os coeficientes de digestibilidade verdadeira do $\mathrm{Ca}$, obtidos pelos métodos de coleta total e do indicador fecal, foram, respectivamente: calcário calcítico $1,84,80$ e $87,33 \%$; calcário calcítico 2, 84,19 e 86,32\%; fosfato bicálcico, 79,36 e $84,55 \%$; fosfato monobicálcico, 83,83 e 85,81\%; calcário dolomítico, 85,65 e $87,39 \%$; farinha de carne e ossos (40\% PB), 70,00 e 68,64\%; farinha de carne e ossos (50\% PB), 66,92 e 68,03\%; farinha de vísceras, 73,40 e 73,95\%; lactato de Ca, 95,10 e 97,33\%. Os valores de Ca digestível, obtidos utilizando-se os valores médios dos coeficientes de digestibilidade verdadeira são: calcário calcítico 1, 31,58\%; calcário calcítico 2 , $30,74 \%$; fosfato bicálcico, $16,87 \%$; fosfato monobicálcico, 15,54\%; calcário dolomítico, 21,66\%; farinha de carne e ossos (40\% PB), 10,32\%; farinha de carne e ossos (50\% PB), $6,42 \%$; farinha de vísceras, $3,98 \%$; lactato de $\mathrm{Ca}$, $18,62 \%$.

\section{REFERÊNCIAS}

AMMERMAN, C.B.; BAKER, D.H.; LEWIS, A.J. Bioavailability of nutrients for animals. amino acids, minerals and vitamins. San Diego: Academic Press, 1995. p.95-118.

AOAC International. (1999). Official methods of analysis of AOAC International. AOAC International, USA.

BENSON, J.D.; EMERY, R.S.; THOMAS, J.W. Effects of previous calcium intakes on adaptation to low and high calcium diets in rats. J. Nutr., v.97, p.53-60, 1969.

BINDELS, R.J. Calcium hadling by the mammaliam kidney. J. Exp. Biol., v.184, p.89104, 1993.

CHENG, T.K.; COON, C.N. Comparison of various in vitro methods for the determination of limestone solubility. Poult. Sci., v.69, p.22042208, 1990.

FAWCETT, R.H.; WEBSTER, M. Variabilidade de alimento e dos ingredientes do alimento: impacto na performance de frangos de corte e lucro. In: SIMPÓSIO INTERNACIONAL ACAVEMBRAPA SOBRE NUTRIÇÃO DE AVES, 1999, Concórdia. Anais... Concórdia: Embrapa suínos e aves: [s.n.] 1999. p.59-68.

FERNANDEZ, J.A. Calcium and phosphorus metabolism in growing pigs. I. Absortion and balance studies. Livest. Prod. Sci., v.41, p.243254, 1995. 
GRAGEOLA, F.; LEMUS, C.; PONCE, J.L. et al. Comparación de métodos de digestibilidad rectal en cerdos pelon mexicano. Rev. Comp. Prod. Porc., v.18, p.189-194, 2011.

GREGER, J.L.; GUTKOWSKI, C.M.; KHAZEN, R.R. Interactions of lactose with calcium, magnesium and zinc in rats. J. Nutr., v.119, p.1691, 1987.

JONGBLOED, A.W.; KEMME, P.A. Apparent digestible phosphorus in the feeding of pigs in relation to availability, requirement and environment. Digestible phosphorus in feedstuffs from plant and animal origin. Neth. J. Agric. Sci., v.38, p.567-75, 1990.

JOSELYN, M.A. Methods in food analysis (physical, chemical and instrumental methods of analysis). New York e Londres: Academic Press, 1970. p.

LELIS, G.R.; ALBINO, L.F.T.; SALGUERO, S.C. et al. Novos conceitos em nutrição avícola. In: AVEWORLD. O Mega Portal da Avicultura Brasileira, 2009, Foz de Iguaçu. Anais... Foz de Iguaçu: [s.n.] 2009.

LINDSAY, H.A. Calcium bioavailability and absorption: A review. Am. J. Clin. Nutr., v.35, p.783-808, 1982.

LOGHMAN, A.M. Role of phosphate retention in the progression of renal failure. Lab. Clin. Med., v.12, p.16-26, 1993.

LY, J.; CHHAY, T.; SAMKOL, P. Studies on the use of acid insoluble ash as inert marker in digestibility trials with Mong CAI pigs. Liv. Res. Rur. Dev., v.14, p.5, 2002.
ROSS, R.D.; CROMWELL, G.L.; STAHLY, T.S. Effects of source and particle size on the biological availability of calcium in calcium supplements for growing pigs. J. Anim. Sci., v.59, p.125-134, 1984.

ROSTAGNO, H.S.; FEATHERSTON, W.R. Estudos de métodos para determinação de disponibilidade de aminoácidos. Rev.Bras.Zootec., v.6, p.64-75, 1977.

ROSTAGNO, H.S.; ALBINO, L.F.T.; DONZELE, J.L. et al. Tabelas brasileiras para aves e suínos: Composição de alimentos e de exigências nutricionais. Viçosa, MG: UFV, 2011. 186p.

SAKOMURA, N.K.; ROSTAGNO, H.S. Métodos de pesquisa em nutrição de monogástricos. Jaboticabal: Funep, 2007. 283p.

SALES, J.; JANSSENS, G. Acid-insoluble ash as a marker in digestibility studies: a review (Abstract). J. Anim. Feed. Sci., v.12, p.383-401, 2003.

SELLE, P.H.; COWIESON, A.J.; RAVINDRAN, V. Consequences of calcium interactions with phytate and phytase for poultry and pigs. Livestock . Sci., v.124, p.126-141, 2009.

SILVA, D.J.; QUEIROZ, A.C. Análise de alimentos (métodos químicos e biológicos). 3.ed.Viçosa: UFV, 2002. 235p.

SISTEMAS de análises estatísticas - SAEG. Versão 5.0. Viçosa, MG: UFV, 1997. 150p. (Manual do usuário). 